\title{
Towards 20MW Wind Turbine: High Reynolds Number Effects on Rotor Design
}

\author{
O. Ceyhan
}

Presented at the $50^{\text {th }}$ AIAA ASM Conference, 9-12 January 2012, Nashville, Tennessee, USA 


\title{
Towards 20MW Wind Turbine: High Reynolds Number Effects on Rotor Design
}

\author{
Özlem Ceyhan ${ }^{1}$ \\ Energy research Center of the Netherlands (ECN), 1755LE, Petten, the Netherlands
}

\begin{abstract}
Wind turbine sizes have grown continuously in the past. That is why the questions such as how much the wind turbine size can grow and what are the aspects that limit the growth come from have to be answered. In order to analyze these questions for the rotor of such a wind turbine, the preliminary design of a 20MW wind turbine rotor has been performed within EU 6th Framework Project UPWIND. Although the rotational speed of the wind turbine is as low as around $6 \mathrm{rpm}$, due to the growth in size very high Reynolds number values of up to 25 million have been reached. The effects of very high Reynolds numbers on the aerodynamic characteristics of the airfoils are investigated and their influences on the rotor design and performance are discussed. As a result, up to $20 \%$ reduction in the chord can be achieved due to the increase in the $C_{1}$ and decrease in $C_{d}$ in high Reynolds numbers. Since the change in the Reynolds numbers influences the rotor design in many respects, more detailed investigations and especially wind tunnel tests of the airfoils for very high Reynolds numbers are required in order to have reliable future large wind turbines.
\end{abstract}

\section{Nomenclature}

$\begin{array}{ll}c & =\text { local chord value } \\ C_{d} & =\text { drag coefficient } \\ C_{f} & =\text { skin friction coefficient } \\ C_{l} & =\text { lift coefficient } \\ C_{p} & =\text { pressure coefficient } \\ C_{P} & =\text { power coefficient } \\ l & =\text { characteristic length } \\ M & =\text { Mach number } \\ P & =\text { Power } \\ r & =\text { local radius } \\ \operatorname{Re} & =\text { Reynolds number } \\ U & =\text { Free stream wind velocity } \\ y^{+} & =\text {dimensionless wall distance } \\ \lambda & =\text { tip speed ratio } \\ v & =\text { kinematic viscosity }\end{array}$

\section{Introduction and Motivation}

$\mathrm{G}$ rowing trends in the wind turbine rotor sizes introduce a lot of challenges to the wind energy research. These new challenges require researchers to provide better understanding of the wind conditions and accurate models to decrease the uncertainties in the design phase and to improve the reliability of these huge machines. All of these aspects have been studied in several projects ${ }^{1,2}$. In order to find the limits of the rotor sizes, a $20 \mathrm{MW}$ rotor design study has been performed within the UPWIND project in which several aspects of a design have been investigated ${ }^{3}$. During this investigation, due to the increased blade dimensions, the local Reynolds number values along the blade span are found to be as high as 25 million while the local speeds are staying the same. The operating Reynolds numbers for a $20 \mathrm{MW}$ wind turbine rotor blade is shown in Figure 1. According to this figure, a 20MW wind turbine blade will operate with Reynolds numbers larger than 10 million except the blade root section although the root is still approaching 10 million Reynolds numbers for the high wind speeds. In the figure, it is also shown that

\footnotetext{
${ }^{1}$ Aerodynamicist, ECN-Wind Energy, 1755LE, Petten, the Netherlands. 
depending on the airfoils used along the blade, the availability of the wind tunnel test data is limited to the very low operating wind speeds for a wind turbine of this size. If NACA airfoils are used, some test data can be found for 9 million Reynolds numbers which is still not covering the whole operating range. This means that either test data for Reynolds numbers higher than 9 million is necessary or Reynolds number effects on the wind turbine design has to be investigated.

Effect of Reynolds numbers are also known as scale effects in the aeronautics society. These effects are usually coming into picture when an aircraft has to be scaled down for wind tunnel tests. Even if the design speeds of these vehicles are kept the same in the test conditions, Reynolds numbers always differ due to the effect of scaling the geometry. Moreover, the increase in size of the commercial airplanes and the increasing speed of the aircrafts are other reasons why the very high Reynolds numbers and their effects are being considered. In the past there had been at least two NATO - AGARD (Advisory Group for Aerospace Research and Development) working groups dedicated to the scale effects on the aircrafts and high Reynolds number wind tunnel studies ${ }^{4}{ }^{5}$. Nowadays, the aircrafts and the wing sections are being designed for their flight Reynolds numbers ${ }^{6},{ }^{7},{ }^{8}$. For wind turbines, the scale effects are also known going from small (a few hundred kilowatts) to large scales (a few megawatts). In the development of wind turbine rotors, wind tunnels are mainly used for the testing of the blade sections. Therefore, the Reynolds number effects are usually taken into account by testing the airfoils used on a blade for the proper Reynolds numbers. However, for the Reynolds number ranges that 20MW wind turbine is introducing, there is no wind tunnel data available for the wind turbine airfoils. It is also not possible to directly translate the knowledge gained from the aircrafts to the wind turbines about the Reynolds number effects. The main difference between the aircrafts' design conditions and a 20MW wind turbine design conditions is that most of the aircrafts are designed for at least the transonic wind speeds where the Mach numbers are around 0.8 in which the compressibility effects are not negligible and there is shock wave on the wing ${ }^{8}$. However, along a $20 \mathrm{MW}$ wind turbine blade, the air is still below Mach number of 0.3 where it is assumed to be incompressible. In the off design conditions for the aircrafts, landing and takeoff are the only operating conditions where the flow is also incompressible and the Reynolds numbers are still high. The 2D wind tunnel tests which are performed for the takeoff or landing conditions of the aircrafts for high Reynolds numbers and low Mach numbers are for the high lift configurations (with flaps and slots) of the airfoil sections. Moreover, wind turbine blade sections are very thick, $t / c$ between $18 \%$ to $40-50 \%$ compared to the aircraft wing sections where the thickness values could be as thin as 6-9\%.

Due to all of the reasons stated, it is decided to evaluate the effects of very high Reynolds numbers on the design of a 20MW wind turbine rotor in the following way: 3 airfoil databases that contain $c_{1}$ and $c_{d}$ data of airfoils for several different Reynolds numbers have been generated by using the available $c_{1}$ and $c_{d}$ data of the airfoils and correcting them for high Reynolds numbers with $\mathrm{RFOIL}^{9}$ predictions. These databases have been used for the design of three different rotors for the same conditions in order to show the effects of using airfoil data for different Reynolds numbers. Before this, RFOIL predictions are compared with the wind tunnel test data of an airfoil which is found in public domain for very high Reynolds numbers in order to evaluate the validity of the corrections. RFOIL predictions are also compared with CFD simulations for a few cases by using Ansys-CFX ${ }^{10}$. Three rotors have been designed to give the best annual yield and compared with each in order to explain the effects of very high Reynolds numbers on such a design.

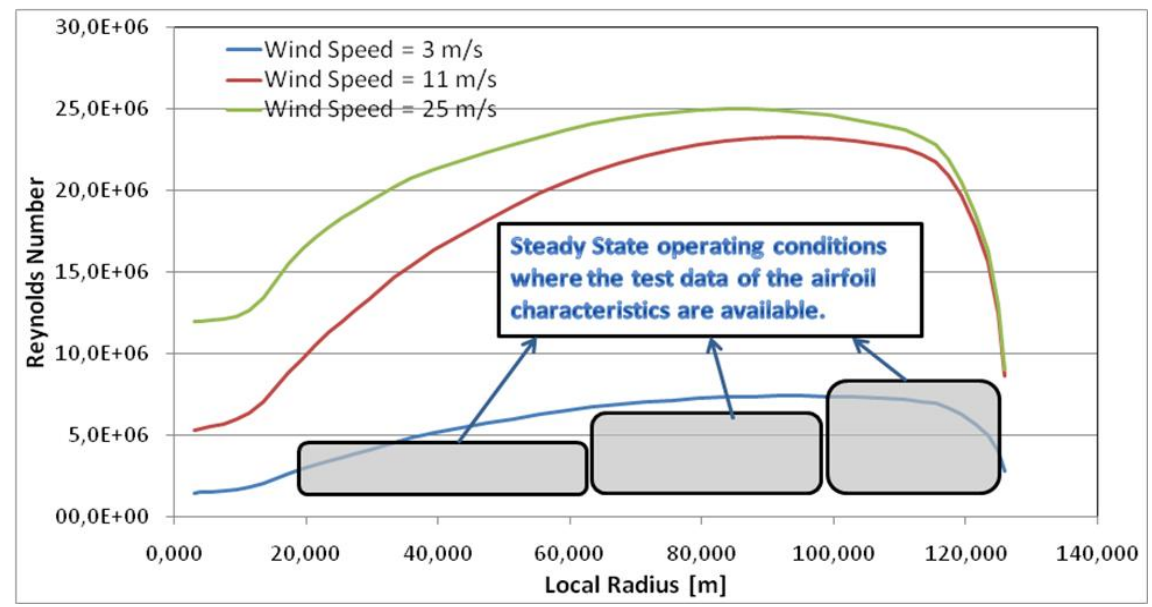

Figure 1. Reynolds number distribution along the blade span and the region of the available wind tunnel test data of 2D sectional characteristics 


\section{Methodology}

\section{A. RFOIL predictions for very High Reynolds Numbers}

RFOIL is an extension of XFOIL ${ }^{11}$. The boundary layer equations in XFOIL are modified for a better post-stall prediction and due to the $3 \mathrm{D}$ effects coming from the rotational terms ${ }^{12},{ }^{13}$. It is widely used in calculating the aerodynamic characteristics of airfoils especially for the wind turbines. There are a lot validations of RFOIL, see for example ${ }^{14,}$, . In this work, RFOIL is used to correct the airfoil characteristics for very high Reynolds numbers. To be more precise, RFOIL hasn't been used to calculate the airfoil lift and drag data for high Reynolds numbers directly, but instead the existing airfoil data has been used and corrected by adding $\Delta \mathrm{C}_{1}$ and $\Delta \mathrm{C}_{\mathrm{d}}$ coming from the RFOIL predictions for the high Reynolds number effects.

In order to evaluate the validity of RFOIL, test data of some airfoils in very high Reynolds numbers is required. However, the number of available test results for these very high Reynolds numbers together with very low freestream velocities (i.e. Mach numbers are smaller than 0.3) are quite limited. Most of the tests that are in public domain are found in old NACA reports coming from 1940's and 1950's and performed in NASA Langley low turbulence wind tunnel (LTPT) $)^{27,16,17}$. Most of the test results found in the public domain are for very small thickness values between $6 \%$ to $13 \%$ for helicopter applications (or for high speed aircraft wings) where the high Reynolds number characteristics are very sensitive to small variations of the freestream Mach numbers even for very low Mach numbers ${ }^{18}$. In some test reports, on the other hand, the airfoil coordinates are not available. In addition to all of these, the quality of the published results is another difficulty for the usability of the test results found in the public domain. There is one particular test performed on modified DU97-W-300 airfoil in DNW cryogenic wind tunnel in Germany ${ }^{15}$. In this test, the Reynolds numbers are reaching only to $10 x 10^{6}$ which is still lower than the values of interest, but these tests are the only publicly available test result for that high Reynolds numbers for thick airfoils. It is found out that usability of these test results in order to characterize purely Reynolds number effects is somewhat limited. It has been stated in ${ }^{15,19,20}$ during these tests the turbulent intensity of the incoming flow has been increased. The effects of this change to the test results have been discussed by using numerical prediction methods in the same references. Such a change in the wind tunnel test conditions to the boundary layer characteristics of the flow around an airfoil and the transition location are explained $\mathrm{in}^{4}$. In this reference, this phenomenon is called as pseudo-Reynolds number effects which means the effects which are not related to the change in Reynolds numbers but related with other conditions. Although RFOIL can still predict such a change in the test conditions relatively well which is also shown i ${ }^{15,20}$, this particular test case hasn't included in the discussion of RFOIL predictions for very high Reynolds numbers.

RFOIL predictions are compared with test results of $63_{3} 018$ airfoil test results for very high Reynolds numbers. This airfoil is a part of NACA 63 family of airfoils that are also commonly used in the wind turbine applications. Moreover, CFX analysis of NACA 64618 airfoil for $0^{\circ}$ angle of attack in three different Reynolds numbers are used for this purpose. This airfoil is used in the UPWIND rotor at the outboard region of the blades as well as in 20MW turbine rotor. Since it has been used at the outboard region, it is assumed to have the most important impact to the rotor design. Therefore, this particular airfoil is selected for this comparison.

Test case for NACA633018 airfoil and CFX setup for the analysis of NACA64618 airfoil are described below:

\section{NACA 63018 Airfoil Tests}

This airfoil tests was performed in Langley LTPT $3 \mathrm{ft} \times 7.5 \mathrm{ft}$ wind tunnel and the test results that are used in this study are obtained from ${ }^{17,18}$. The details about the description of the tests and the facility can be obtained from ${ }^{17}$. The lift is measured by taking the difference between the pressure reaction on the floor and the ceiling since the model is located from one side of the wall to the otherside on $3 \mathrm{ft}$ dimension of the test section whereas the drag is measured by wake survey method. $C_{1}$ and $C_{d}$ measurements for different angles of attack for a Reynolds number range of 6 million to 20 million is available. However, due to the quality of the provided drag graphs in the publication, it was impossible to obtain a reliable data for drag comparisons. Instead, another reference ${ }^{18}$ has been used to compare the minimum drag characteristics for very high Reynolds numbers and the discussions in these references has been used to comment on the drag prediction results of RFOIL.

2. CFD Simulations and Analysis Conditions

ANSYS CFX-11.0 is used for this study. It is a commercial CFD code which has been developed for the multi purpose applications. Within the several features of CFX, only the part related to this study is described here.

The flow around the given 2D airfoil is analyzed by using RANS equations in conservative form solved using high resolution advection scheme with auto timescale option. The turbulence in the flow is modeled by using turbulence model. There are several turbulence models are available in CFX. In this study, $k-\omega$ based Shear Stress Transport model developed by Menter ${ }^{21}$ is used which is suggested by CFX. 2D structured CH type meshes are generated by using ANSYS ICEM CFD mesh generator. In order to the capture the flow in the boundary layer as 
accurate as possible, dimensionless wall distance, $\mathrm{y}^{+}$, is taken as close to 1 as possible which is also checked for each simulation.

The purpose of these simulations is to find the changes in the force coefficients of the 2D airfoils by changing the Reynolds numbers. The method is to analyze NACA 64618 airfoil for 3 different Reynolds numbers which are also used in the rotor design. The change in the Reynolds number can be created by several ways in a CFD solver. If the air in $25^{\circ} \mathrm{C}$ is used, then according to the definition of the Reynolds number in the formula below, the change in Reynolds numbers can be obtained either by changing the free stream velocity or the reference length. Since the flow is incompressible around the wind turbine sections, this means the Reynolds number change has to be obtained by only changing the characteristic length. Therefore different meshes are created depending upon the length scale in each simulation.

$$
\operatorname{Re}=\frac{U \cdot l}{v}
$$

For the simulations of each Reynolds number, two different mesh sizes are used. Some parameters are summarized in Table 1. An example of the mesh and the resolution in the boundary layer is shown in Figure 2 for the coarse mesh used in 6 million Reynolds number simulations. The convergence criteria for the simulations are the RMS of the mass, and momentum equations are lower than $10^{-10}$ which has been found to be more than enough to have convergence in the drag and lift forces.

\begin{tabular}{|c|c|c|c|}
\hline REYNOLDS NUMBER & $\mathbf{6 \times 1 0 ^ { \mathbf { 6 } }}$ & $\mathbf{1 0 \times 1 0 ^ { \mathbf { 6 } }}$ & $\mathbf{2 0 \times 1 0 ^ { \mathbf { 6 } }}$ \\
\hline Length Scale (c=unit length) & $\mathrm{c}$ & $2 \mathrm{c}$ & $4 \mathrm{c}$ \\
\hline Velocity & incompressible & incompressible & incompressible \\
\hline \# of elements in Coarse Mesh & 82000 & 82000 & 82000 \\
\hline \# of elements in Fine Mesh & 242000 & 242000 & 242000 \\
\hline $\mathbf{y}^{+}$(calculated in the simulation) & $1.0<\mathrm{y}^{+}<2.0$ & $1.0<\mathrm{y}^{+}<2.0$ & $1.0<\mathrm{y}^{+}<2.0$ \\
\hline Farfield Boundary in the wake & $50 \mathrm{c}$ & $50 \mathrm{c}$ & $50 \mathrm{c}$ \\
\hline Farfield Boundary in front of the airfoil & $30 \mathrm{c}$ & $30 \mathrm{c}$ & $30 \mathrm{c}$ \\
\hline
\end{tabular}

Table 1. Some parameters used in the CFX simulations.
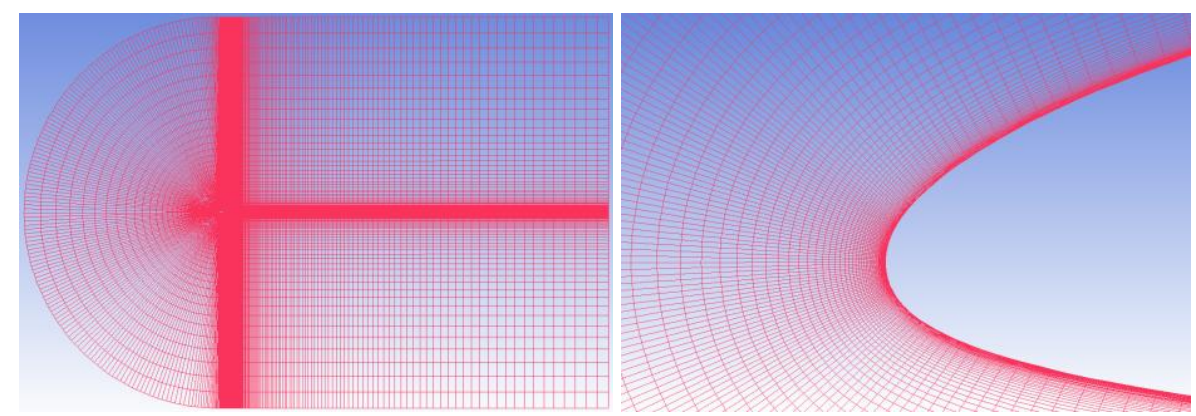

Figure 2. Example of a coarse mesh used in the simulations for $\mathrm{Re}=6$ million

\section{B. Rotor Design Methodology}

The rotor designs are performed by a BEM based optimization method which is developed by $\mathrm{Bot}^{22,}{ }^{23}$. The classical Blade Element Momentum theory is coupled with a gradient based optimization method called as golden search to optimize the geometry of the rotor blade in order to obtain maximum annual yield for a given Weibull distribution of wind speeds by changing the chord, twist and thickness values of the blade. There are some corrections applied to the basic BEM formulas in order to deal with the turbulent wake state and root and tip losses. The correction for the turbulent wake state is based on an engineering model which replaces the thrust coefficient in the axial momentum equation ${ }^{24}$. And in order to deal with the root and tip losses, Prandtl root and tip losses factor is applied $^{24}$. In addition to these, 3D corrections are applied to the 2D airfoil characteristics. These 3D corrections are based on the fact that especially in the root section of the blades due to the radial velocities coming from the rotational speed the stall is delayed. According to the model developed by Snel ${ }^{12}$, the radial flow depends on the tip speed ratio, chord and radial location of the section. The implementation of this effect to the airfoil coefficients is

$$
C_{l, 3 D}=C_{l, 2 D}+\frac{3.1 \cdot \lambda^{2}}{1+\lambda^{2}} \cdot g \cdot\left(\frac{c}{r}\right)^{2} \cdot\left(\left.\frac{d C_{l}}{d \alpha}\right|_{\text {linear }} \cdot \sin \left(\alpha-\alpha_{0}\right)-C_{l, 2 D}\right)
$$




$$
\text { Where } g= \begin{cases}1 & , 0<\alpha<30 \\ \frac{1}{2}(1+\cos (6 \alpha-180)) & , 30<\alpha<60 \\ 0 & , 60<\alpha<360\end{cases}
$$

According to the method used, the BEM part is used to determine the performance of the rotor according to the given wind and operating conditions and chord and twist distribution and airfoil information. The optimization which is coupled with BEM theory maximizes the yield in,

$$
\max (\text { yield }[p(U), P(U, c(r), \phi(r), g(r))])
$$

Where $p(U)$ is given wind regime probability distribution, $P(U, c(r), \phi(r), g(r))$ is the power produced according to the given geometrical information including $2 \mathrm{D}$ airfoil characteristics which is stated as $g(r)$. In this process, the parameters used in the optimization are the local chord and twist angle values and the thickness which is based on the chord and the airfoil distribution along the blade. The blade geometry of the rotor is optimized according to the given wind conditions, the tip speed ratio and the rotational speed. In this procedure, for a pitch controlled wind turbine, the pitch angle is always chosen as the angle which will give the highest efficiency according to the given wind speed and the rotational speed until the rated wind speed. The rotor torque is already given after the rated wind speed, thus the pitch angle that gives the required torque is chosen after the rated wind speed. During this optimization process, the airfoil data or 2D aerodynamic characteristics of the sections are used from the pre-defined airfoil database. In this database, $C_{1}$ and $C_{d}$ data of the airfoils for an angle of attack regime of -180 to 180 degrees are included as well as the relative thickness information. $C_{1}$ and $C_{d}$ values of the airfoils used in this study is obtained mainly from an external airfoil database which is developed by BOT $^{25}$ called ATG (Airfoil Table Generator) that includes the wind tunnel test results of airfoils' aerodynamic characteristics and some airfoil data is also available for the UPWIND reference wind turbine. The data for the high Reynolds numbers, however, has been obtained by correcting the existing airfoil characteristics used in the database by using RFOIL predictions for the difference between the $\mathrm{C}_{\mathrm{l}}$ and $\mathrm{C}_{\mathrm{d}}$ existing Reynolds number and the high Reynolds number .

During this design study, the exact wind conditions, the structural properties and the flexibility of the blades or the effects of the loads on the design haven't been considered. The design work is only concentrated on showing the effect of high Reynolds numbers on the aerodynamic design of 20MW rotor to give the best annual yield.

\section{Airfoil databases}

In each airfoil database used in this stud, there is $\mathrm{C}_{1}$ and $\mathrm{C}_{\mathrm{d}}$ data for the airfoils used in the UPWIND reference wind turbine ${ }^{3}$ from -180 to 180 degrees of angles of attack for a range of Reynolds numbers. The lowest Reynolds number used is $3 \times 10^{6}$ and the highest is either $7 \times 10^{6}$ or $10 \times 10^{6}$ or $25 \times 10^{6}$ depending on the database. In the first database, the Reynolds numbers used are $3 \times 10^{6}$ and $7 \times 10^{6}$. The data for Reynolds number of $10 \times 10^{6}$ is added to the first database in order to end up with the second database. And for the last one, the data for Reynolds numbers of

\begin{tabular}{|c|c|c|c|c|c|c|c|}
\hline & $\begin{array}{l}\text { Name of } \\
\text { the airfoil } \\
\text { database }\end{array}$ & NACA 64618 & DU93-W-210 & DU91-W2-250 & DU97-W-300 & DU00-W2-350 & DU00-W2-401 \\
\hline 1. & $\begin{array}{l}7 \text { mil. Re \# } \\
\text { DB }\end{array}$ & $\begin{array}{l}\mathrm{Re}=3 \times 10^{6} \\
\text { and } 6 \times 10^{6}\end{array}$ & $\begin{array}{l}\mathrm{Re}=3 \times 10^{6} \\
\text { and } 7 \times 10^{6}\end{array}$ & $\begin{array}{l}\mathrm{Re}=3 \times 10^{6} \text { and } \\
7 \times 10^{6}\end{array}$ & $\begin{array}{l}\mathrm{Re}=3 \times 10^{6} \\
\text { and } 7 \times 10^{6}\end{array}$ & $\begin{array}{l}\mathrm{Re}=3 \times 10^{6} \text { and } \\
7 \times 10^{6}\end{array}$ & $\begin{array}{l}\mathrm{Re}=3 \times 10^{6} \text { and } \\
7 \times 10^{6}\end{array}$ \\
\hline 2. & $\begin{array}{l}10 \text { mil Re \# } \\
\text { DB }\end{array}$ & $\begin{array}{l}\mathrm{Re}=3 \times 10^{6}, \\
6 \times 10^{6}, \\
10 \times 10^{6}\end{array}$ & $\begin{array}{l}\mathrm{Re}=3 \times 10^{6}, \\
7 \times 10^{6}, \\
10 \times 10^{6}\end{array}$ & $\begin{array}{l}\mathrm{Re}=3 \times 10^{6} \\
7 \times 10^{6}, 10 \times 10^{6}\end{array}$ & $\begin{array}{l}\mathrm{Re}=3 \times 10^{6}, \\
7 \times 10^{6}, \\
10 \times 10^{6}\end{array}$ & $\begin{array}{l}\mathrm{Re}=3 \times 10^{6}, \\
7 \times 10^{6}, 10 \times 10^{6}\end{array}$ & $\begin{array}{l}\mathrm{Re}=3 \times 10^{6}, \\
7 \times 10^{6}, 10 \times 10^{6}\end{array}$ \\
\hline 3. & $\begin{array}{l}25 \text { mil Re \# } \\
\text { DB }\end{array}$ & $\begin{array}{l}\mathrm{Re}=3 \times 10^{6}, \\
6 \times 10^{6}, \\
10 \times 10^{6}, \\
15 \times 10^{6} \\
20 \times 10^{6}\end{array}$ & $\begin{array}{l}\mathrm{Re}=3 \times 10^{6}, \\
6 \times 10^{6}, \\
10 \times 10^{6}, \\
15 \times 10^{6} \\
25 \times 10^{6}\end{array}$ & $\begin{array}{l}\operatorname{Re}=3 \times 10^{6}, \\
6 \times 10^{6} \\
10 \times 10^{6} \\
15 \times 10^{6} \\
25 \times 10^{6}\end{array}$ & $\begin{array}{l}\operatorname{Re}=3 \times 10^{6}, \\
6 \times 10^{6} \\
10 \times 10^{6} \\
15 \times 10^{6} \\
25 \times 10^{6}\end{array}$ & $\begin{array}{l}\operatorname{Re}=3 \times 10^{6}, \\
6 \times 10^{6} \\
10 \times 10^{6} \\
15 \times 10^{6} \\
25 \times 10^{6}\end{array}$ & $\begin{array}{l}\mathrm{Re}=3 \times 10^{6}, \\
6 \times 10^{6} \\
10 \times 10^{6} \\
15 \times 10^{6} \\
20 \times 10^{6}\end{array}$ \\
\hline
\end{tabular}
$15 \times 10^{6}$ and $25 \times 10^{6}$ are included. This classification is shown in Table 2.

\section{Table 2. Properties of the airfoil databases}

Reynolds number in $1^{\text {st }}$ database and the higher Reynolds numbers is calculated for the every 0.1 degrees of angles of attack from the negative stall to positive stall. Finally, this difference is added to the existing $C_{l}$ and $C_{d}$ polars for the highest Reynolds number in the first database. By doing that, instead of using the RFOIL predictions 
directly for the higher Reynolds number data, the RFOIL predictions for the high Reynolds number effects are used. This method gives more confidence to the predictions. The method is shown in the equation below:

$$
\begin{aligned}
& C_{l}(\alpha, \operatorname{Re})=C_{l}\left(\alpha, \operatorname{Re}_{1 s \text { Database }}\right)+\Delta C_{l, R F O I L} \\
& \Delta C_{l, R F O I L}=C_{l, R F O I L}(\alpha, \operatorname{Re})+C_{l, R F O I L}\left(\alpha, \operatorname{Re}_{1 \text { stDatabase }}\right)
\end{aligned}
$$

\section{Results}

\section{A. Validity of RFOIL predictions for very High Reynolds numbers}

\section{NACA $63_{3} 018$ airfoil tests}

According to the test results for NACA $63_{3} 018$ airfoil, Reynolds number has favorable effect on the performance of this airfoil. According to the Figure 3, Reynolds number of $9 \times 10^{6}$ is very well captured with RFOIL as well as $20 \times 10^{6}$. For the Reynolds number of $20 \times 10^{6}$ however, RFOIL slightly underestimates the lift especially for the angles of attack values larger than 5, including the range up to the post stall angles. In the same figure, the size of the laminar drag bucket is reduced as expected and explained in the references ${ }^{17,18,4}$ and the overall drag for almost all conditions, except at the edges of the low drag bucket is reduced. However, by only looking at these results, it is not possible to assess the drag prediction qualitatively. The reason of having more drag with $20 \times 10^{6}$ Reynolds number case at about $C_{1}=0.3$ can be explained by looking at Figure 4 . Here, it seems that for $R e=20 \times 10^{6}$ case just before $0.3 C_{1}$ the transition point on the suction side is moving to the leading edge more rapidly than $\operatorname{Re}=9 \times 10^{6}$ case with increasing lift. Most probably, the favorable effect of the high Reynolds number in decreasing the boundary layer thickness is altered by this rapid forward movement of the transition location which increases the boundary layer thickness after the transition. In Figure 5, although the increase in $C_{\operatorname{lmax}}$ for the Reynolds numbers up to 9x10 Reynolds number is very well predicted, for the higher Reynolds numbers $\mathrm{C}_{\mathrm{lmax}}$ seems to be always under-estimated. Minimum drag is not well predicted according to the test results in the same figure. From $5 \times 10^{6}$ to $17 \times 10^{6}$ the decrease in minimum drag is from 0.00725 to 0.00625 in the tests where RFOIL predicts a decrease from 0.00462 to 0.0040 . From another perspective, the decrease in minimum drag is very well predicted from $5 \times 10^{6}$ to $10 \times 10^{6}$ but for higher Reynolds numbers, it is again under-estimated. For Reynolds numbers higher than $20 \times 10^{6}$, RFOIL predicts a slight increase in the minimum drag, but there are no test results to prove this prediction.
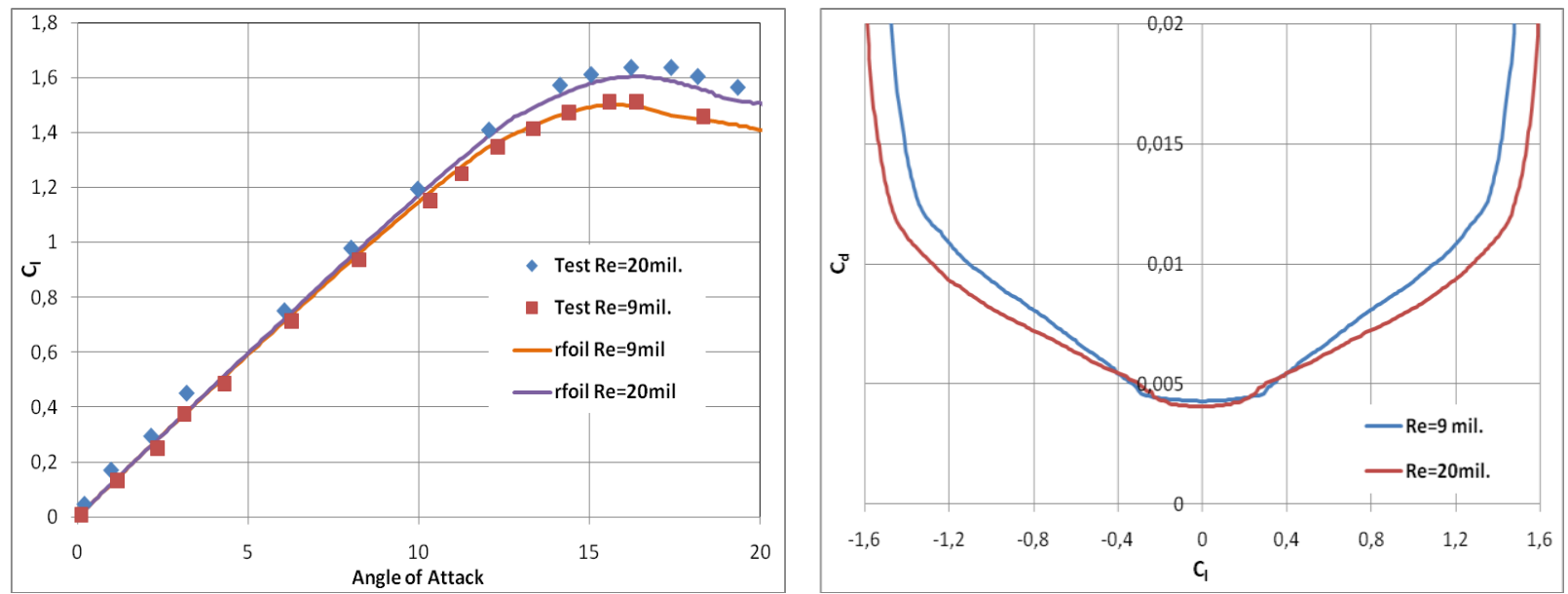

Figure 3. NACA $63_{3} 018$ airfoil characteristics for high Reynolds numbers 


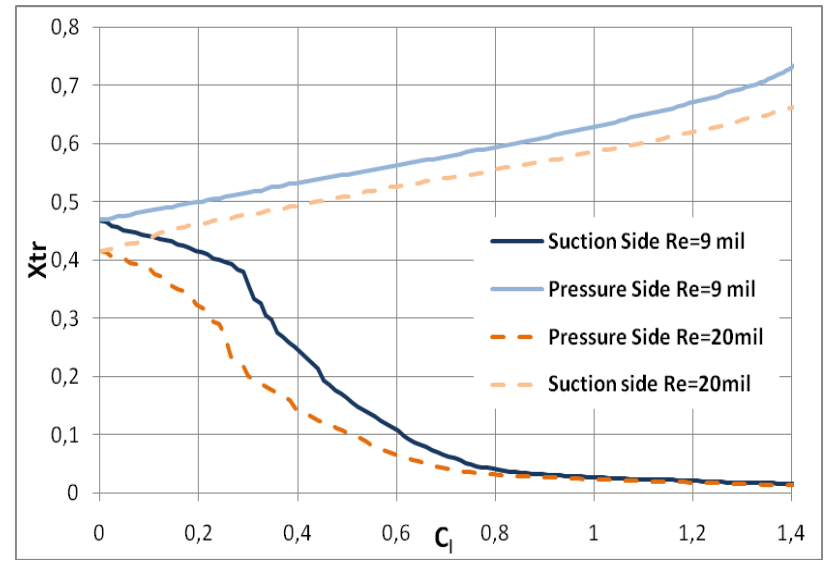

Figure 4. Transition location for NACA $63_{3} 018$ airfoil
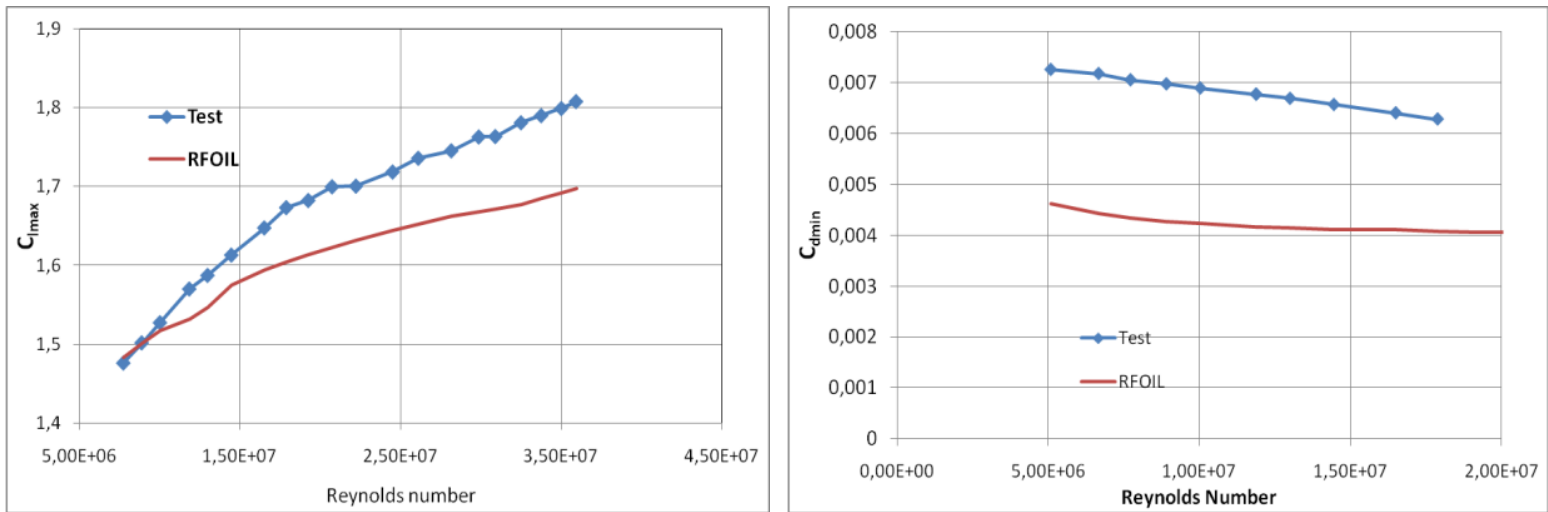

Figure 5. Maximum lift and minimum drag of NACA $63_{3} 018$ airfoil for a series of Reynolds numbers

\section{NACA 64618 analysis with CFX}

This airfoil is analyzed by using CFX for an angle of attack of zero for $6 \times 10^{6}, 10 \times 10^{6}$, and $20 \times 10^{6}$ Reynolds numbers in fully turbulent case. In Figure 6, CFX analysis results for the pressure coefficient are compared with RFOIL predictions. Except the trailing edge part, the results from the two software's are very close to each other. Also, it is not very clear if Reynolds number has a favorable effect on $\mathrm{C}_{1}$ or not. This is not true for the skin friction. In Figure 7, it seems that the overall skin friction is reduced when Reynolds number is increased from $6 \times 10^{6}$ to $20 \times 10^{6}$. Skin friction value in CFX is obtained by nondimensionalising the wall shear parameter in CFX output by using the freestream velocity. The same approach is used in the RFOIL calculations as well. Although the skin friction parameter is very hard to predict, it is promising to obtain very similar results from these two codes.
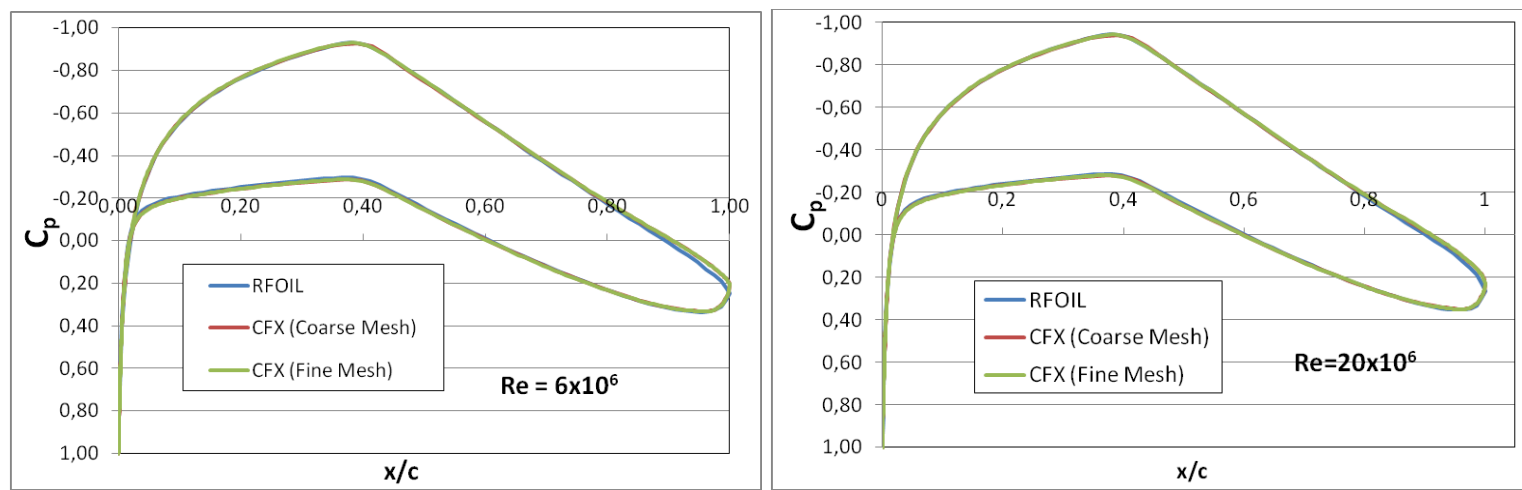

Figure 6. $C_{p}$ comparisons of RFOIL with CFX predictions for 2 different mesh sizes for 2 different Reynolds numbers. 

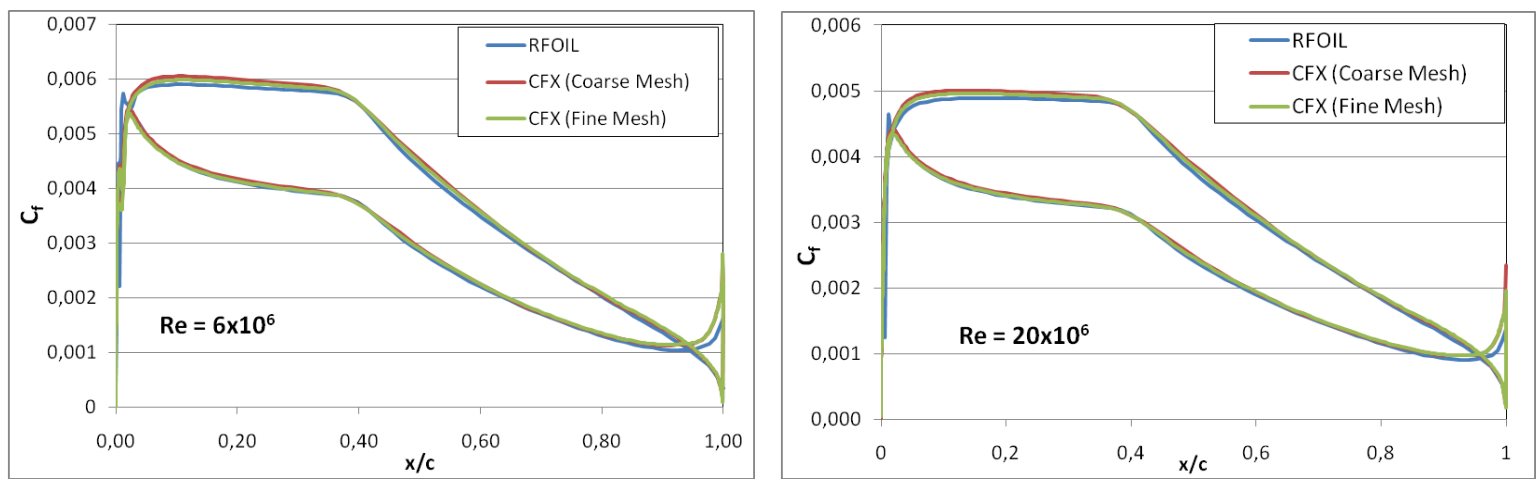

Figure 7. $\mathrm{C}_{\mathrm{f}}$ comparisons of RFOIL with CFX for 2 different Reynolds numbers

In the previous two sections, the values of the overall forces haven't always been very well predicted by RFOIL. However, the Reynolds effects from lower to higher Reynolds number have almost always under estimated. For this case, the estimations of the Reynolds effect on the overall force coefficients have been compared with each other. The differences are calculated by the following relation; where positive difference in $C_{1}$ means a $C_{1}$ increase with Reynolds number and positive increase in $\mathrm{C}_{\mathrm{d}}$ difference means decrease in $\mathrm{C}_{\mathrm{d}}$.

$$
\begin{gathered}
\Delta C_{l @ \mathrm{Re}=10 \mathrm{mil}}=\frac{C_{l @ \mathrm{Re}=10 \mathrm{mil}}-C_{l @ \mathrm{Re}=6 \mathrm{mil}}}{C_{l @ \mathrm{Re}=6 \text { mil }}} \\
\Delta C_{l @ \mathrm{Re}=20 \mathrm{mil}}=\frac{C_{l @ \mathrm{Re}=20 \mathrm{mil}}-C_{l @ \mathrm{Re}=6 \mathrm{mil}}}{C_{l @ \mathrm{Re}=6 \text { mil }}}
\end{gathered}
$$
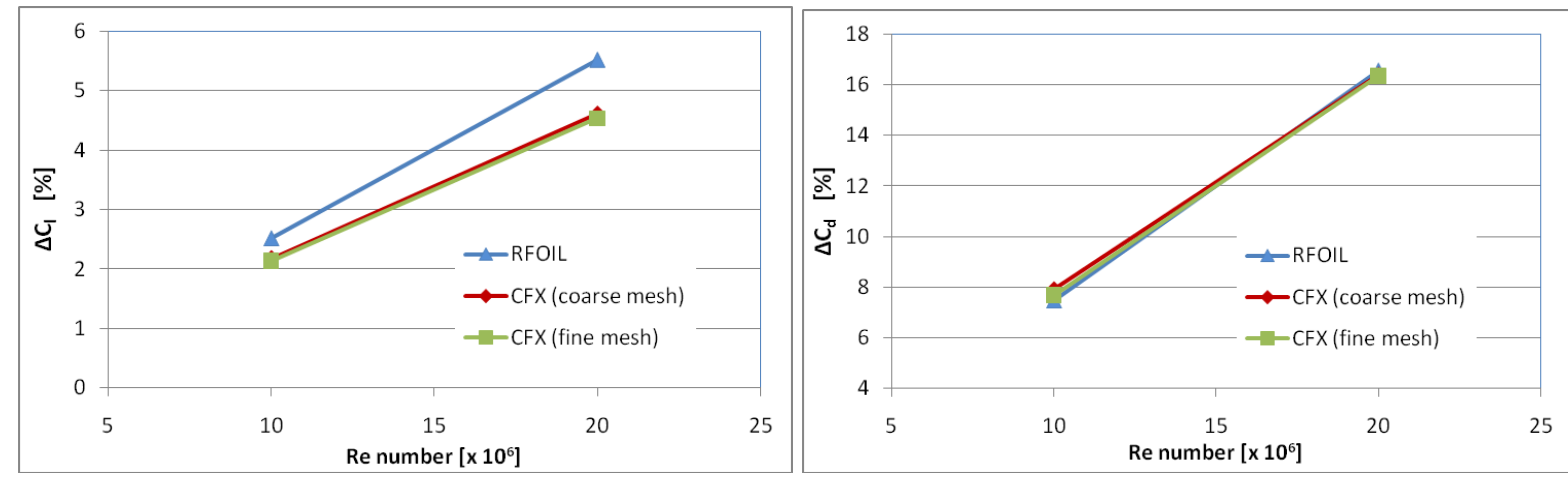

Figure 8. $C_{l}$ and $C_{d}$ changes by increasing Reynolds number are compared with RFOIL and CFX predictions

According to the Figure 8, 5\% change in $C_{1}$ and $16 \%$ change in $C_{d}$ is obtained going from $6 \times 10^{6}$ to $20 \times 10^{6}$ by CFX. RFOIL this time slightly overestimates the increase in $C_{1}$ whereas it predicts similar results for $C_{d}$ decrease compared to the CFX results. In these particular cases, the effect of Reynolds number on the force coefficients in the fully turbulent flow condition is shown. Based on the assumption that CFX has better accuracy in predicting the effect of high Reynolds numbers RFOIL might overpredict the effect of Reynolds number to the turbulent boundary layer, when there is no laminar flow and no transition. However, there is no evidence to prove the differences predicted by CFX to be more accurate than the RFOIL predictions. Therefore, more analysis has to be performed and compared with test results for that high Reynolds numbers.

\section{B. Corrected airfoil data}

All the airfoils used in the UPWIND reference wind turbine blade have been analyzed for a series of Reynolds numbers in order to fill the airfoil databases used in the rotor design. These Reynolds numbers are given in Table 2. Correction for each Reynolds numbers are calculated and added to the existing airfoil data to obtain the polars for the high Reynolds number airfoil data. RFOIL results for the tip airfoil and for a root airfoil are shown in Figure 9 and Figure 10. As a result of such a correction, the stall character of NACA 64618 airfoil hasn't changed, except the 
maximum stall angle and the absolute values. The difference between the corrected drag curves and the available one is not as large as in the analysis results; only the overall drag is reduced except a few regions where there is drag increase. Moreover, in NACA 64618 case, the efficiency has shifted to the higher $\mathrm{C}_{1}$ values. In DU00-W2-350 airfoil, Reynolds number has always favorable effect as it is predicted by RFOIL. After the correction, the efficiency at the higher Reynolds number has only a slight difference because of the decrease in $C_{d}$ and increase in $C_{1}$. The rest of the airfoils in the databases are updated similarly.
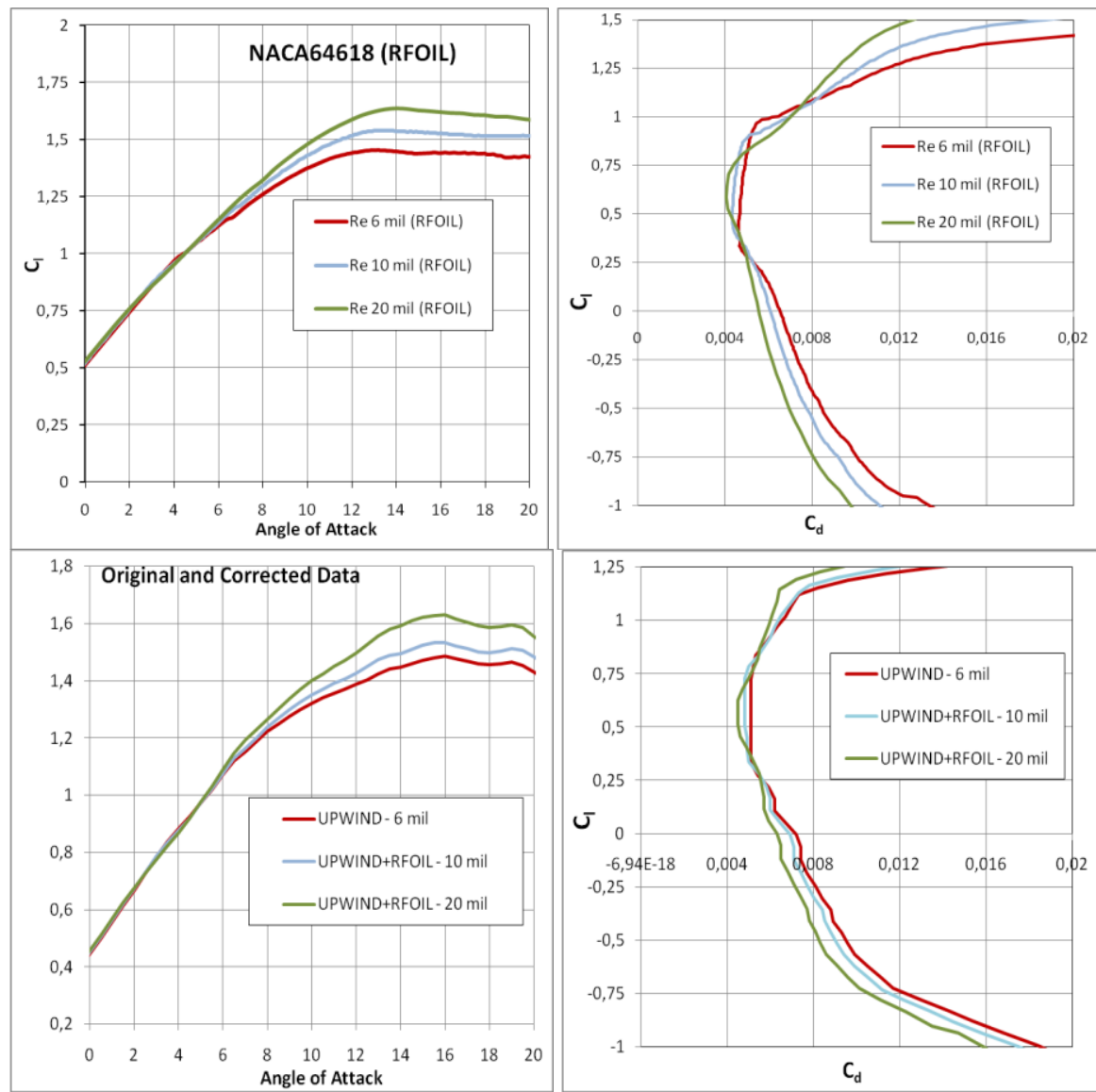

Figure 9. $C_{1}$ and $C_{d}$ graphs for NACA-64618 calculated with RFOIL (top) and corrected with RFOIL (bottom). The corrections are applied on the existing data which is obtained from UPWIND reference wind turbine.

The effects of the high Reynolds numbers on some the airfoils are shown here. Now the question is what the effects of such changes are on the design of a 20MW wind turbine rotor. To isolate the problem from the other aspects of the rotor design, only the aerodynamic design of the 20MW wind turbine has been performed. UPWIND reference wind turbine rotor is used for the starting point of the discussions. This rotor is upscaled to 20MW by using classical upscaling procedures ${ }^{26} .20 \mathrm{MW}$ upscaled wind turbine rotor is used as a baseline for the designs and for the comparisons in this study. 

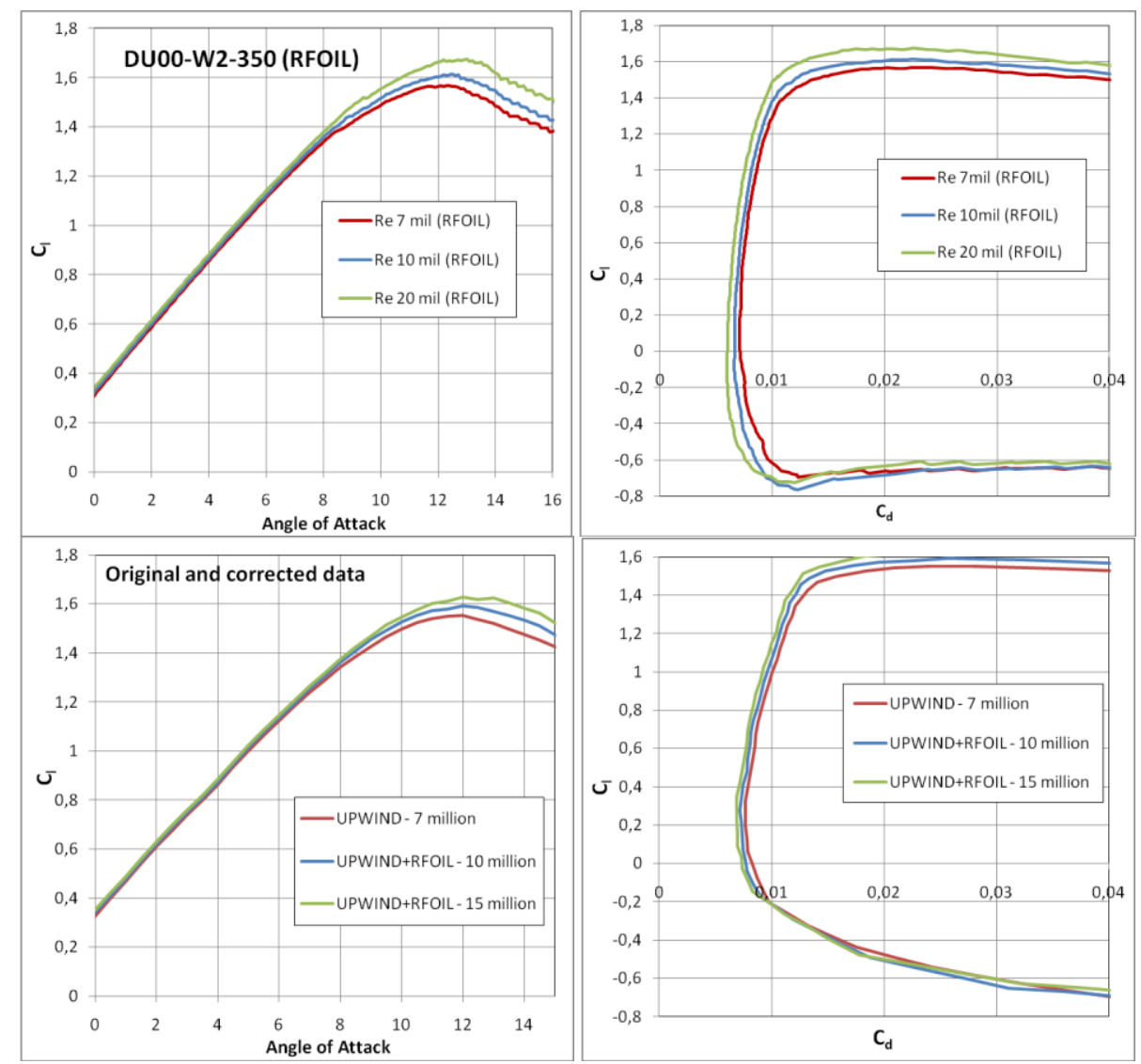

Figure 10. $\quad C_{1}$ and $C_{d}$ graphs for DU 00-W2-350 calculated with RFOIL (top) and corrected with RFOIL (bottom). The corrections are applied on the existing data which is obtained from UPWIND reference wind turbine.

\section{Reynolds Number Effects on 20MW rotor design}

$20 \mathrm{MW}$ wind turbine rotor design conditions such as tip speed ratio, the wind class, etc. have been taken as the same as UPWIND reference wind turbine. The parameters used in this study are shown in Table 3. One of the most important limitation used in the design is to use keep the airfoil distribution constant. This has been chosen in order to show only the effect of Reynolds number change.

\begin{tabular}{|c|c|c|}
\hline Rated Power [MW] & & 20 \\
\hline Rotor Diameter [m] & & 252 \\
\hline Cut-in Wind Speed $[\mathrm{m} / \mathrm{s}]$ & & 3 \\
\hline Cut-out Wind Speed $[\mathrm{m} / \mathrm{s}]$ & & 25 \\
\hline Rotational Speed [rpm] & & $0.5-6.05$ \\
\hline Max Tip Speed [m/s] & & 80 \\
\hline Design Tip Speed Ratio & & 8.5 \\
\hline Maximum Chord [m] & & 9.2 \\
\hline Airfoil distribution (\% of the blade radius): & $\begin{array}{c}\text { 0-8\%: } \\
\text { Up to } 18 \% \text { : } \\
\text { Up to } 28.2 \%: \\
\text { Up to } 38.1 \%: \\
\text { Up to } 41.2 \% \text { : } \\
\text { Up to } 50.7 \% \text { : } \\
\text { Up to } 65.9 \%: \\
\text { Up to } 100 \%:\end{array}$ & $\begin{array}{l}\text { Cylinder } \\
\text { Cylinder2 (transit) } \\
\text { DU00-W2-401 } \\
\text { DU00-W2-350 } \\
\text { DU97-W-300 } \\
\text { DU91-W2-250 } \\
\text { DU93-W-210 } \\
\text { NACA } 64618 \\
\end{array}$ \\
\hline
\end{tabular}

Table 3. Design conditions and parameters 
The design by using the first database is called as "Design with UPWIND Airfoils (7 mil)" in which the airfoils are at 7 million Reynolds numbers. The design by using the second database is called as "Design with 10 mil Re Numbers". The design by using the third database is referred as "Design with 25 mil Re numbers".

An important criterion of the designs studied here is to keep the power performance as high as possible. Since the cost function in the optimization aims to maximize the annual power production, all of these designs are aimed to have the maximum $\mathrm{C}_{\mathrm{P}}$. In the normal rotor designs, being cost effective is usually the driving parameter more than the annual yield alone.

During the rotor designs, the chord distribution at the first $40 \mathrm{~m}$ of the rotor blade is kept the same as the reference turbine. The DU airfoils start from this point on. Finding the effects of the Reynolds number changes in this area is even more challenging since the shapes of the sections here are very thick or even cylinder and the flow in this part is completely 3D. Also, this part has less contribution to the overall performance compared to the rest of the blade. In the Figure 11, the chord distributions of the 3 different designs are compared with the Classical Upscaled 20MW wind turbine. Since the upscaled wind turbine rotor is not exactly in its aerodynamic optimum design dimensions, the spanwise distribution of the chord values are changed, mostly reduced, in the design by using the UPWIND airfoil database. The rotor designed by using the $25 \times 10^{6}$ Reynolds number database, there is a clear reduction in the chord distribution along the blade which can reach about 1.3 to $1.5 \mathrm{~m}$ in the middle sections. If $10 \times 10^{6}$ Reynolds number database is used, there is some increase in chord values at the tip region where NACA64618 airfoils have been used compared to the design with UPWIND airfoils. This shows that for this Reynolds number regime, the optimum design condition is located in somewhat smaller $C_{1}$ than $25 \times 10^{6}$ or $7 \times 10^{6}$ Reynolds number regimes. This is an expected result due to smaller laminar drag bucket where at this Reynolds number, the local increase in drag shifts the design condition to the smaller $C_{1}$ values. However, in higher Reynolds numbers, the larger increase in $C_{1}$ together with larger decrease in $C_{d}$ shifted the design condition to higher $C_{1}$ values. In the Figure 12, the percentage reductions in chord by using different airfoils are shown. The classical upscaled wind turbine is taken as a baseline for this comparison. If UPWIND airfoils are used in the design, the reduction is limited to 5-8 percent whereas the reductions are around $17 \%$ if the $25 \times 10^{6}$ Reynolds number database is used. In both cases, the reduction in the tip chord is almost 50\%. The explanation of that reduction is probably related with the UPWIND reference wind turbine itself which is based on a 6MW DOWEC design and adapted to a $5 \mathrm{MW}$ turbine by reducing the diameter of the rotor $^{26}$. This means that the original reference wind turbine tip is already far from the optimum design.

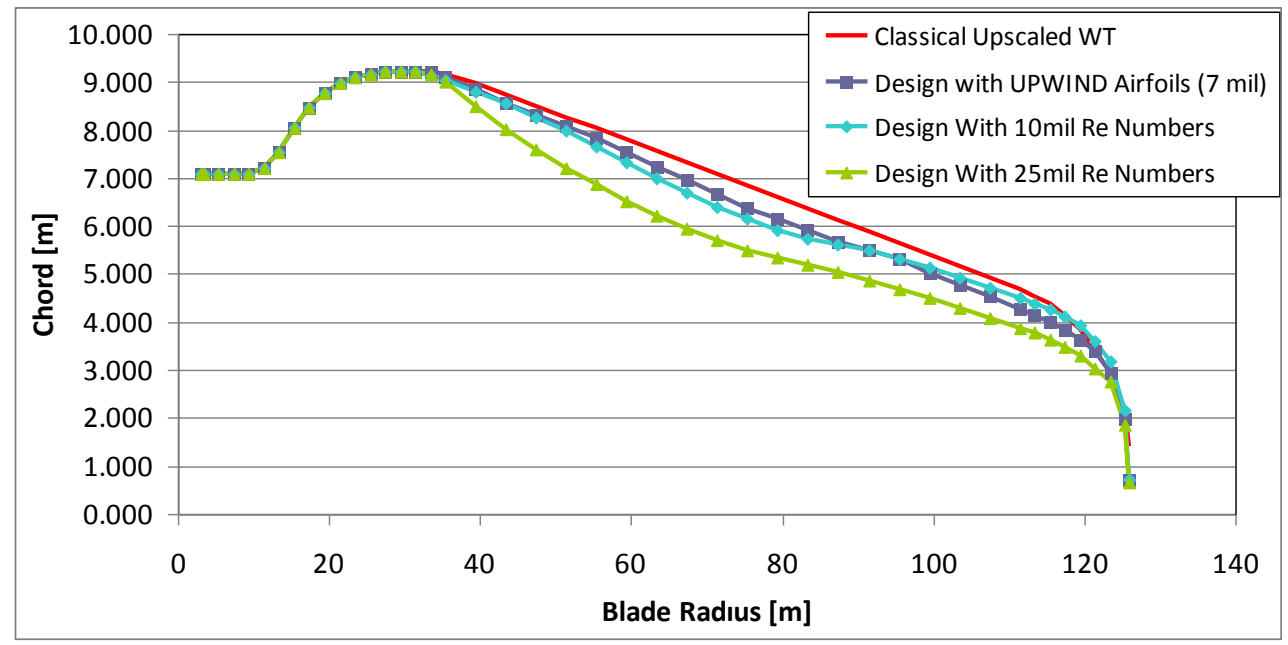

Figure 11. Chord distributions along the blade compared for the different designs.

According to Figure 13, the twist in the root and in the middle sections is common in all designs. Increase in twist at the tip section is again be related with the non-optimum design of UPWIND reference turbine. There is also slight increase in local twist of the design with $10 \times 10^{6}$ Reynolds number airfoils as expected from the chord distribution results. In the $25 \times 10^{6}$ Reynolds number design, there is no increase at the tip and there is only an overall reduction in twist. At the tip region, there is no decrease from the classical turbine rotor. The local twist angles are less than the classical and UPWIND airfoils design but only slightly different than the $10 \times 10^{6}$ Reynolds number. This is explained by the shift of the design condition to the higher lift values which gives possibility to operate in higher angles of attack by having smaller twist in the blade. Since the stall angle also predicted larger in the high Reynolds numbers, the operating angles of attacks are still far from the stall angle. During the design, there are only 
minor modifications in the absolute thickness distributions of the designs. The largest reduction in the absolute thickness is obtained from the $25 \times 10^{6}$ Reynolds number airfoil database which is around 30 to $40 \mathrm{~cm}$ as shown in Figure 14. This decrease has effects on the strength and the weight of the blade and therefore has to be verified during the design in the real rotor design application.

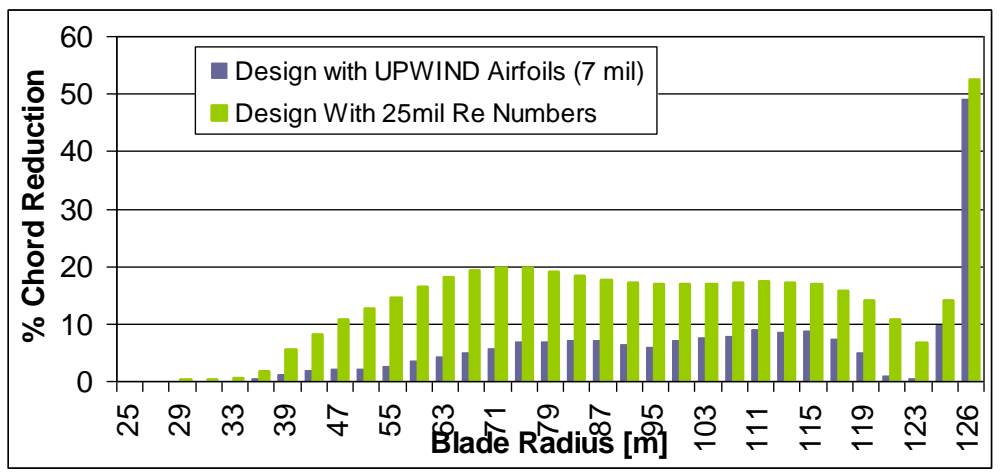

Figure 12. Reduction in the chord by using different airfoil databases in the design.

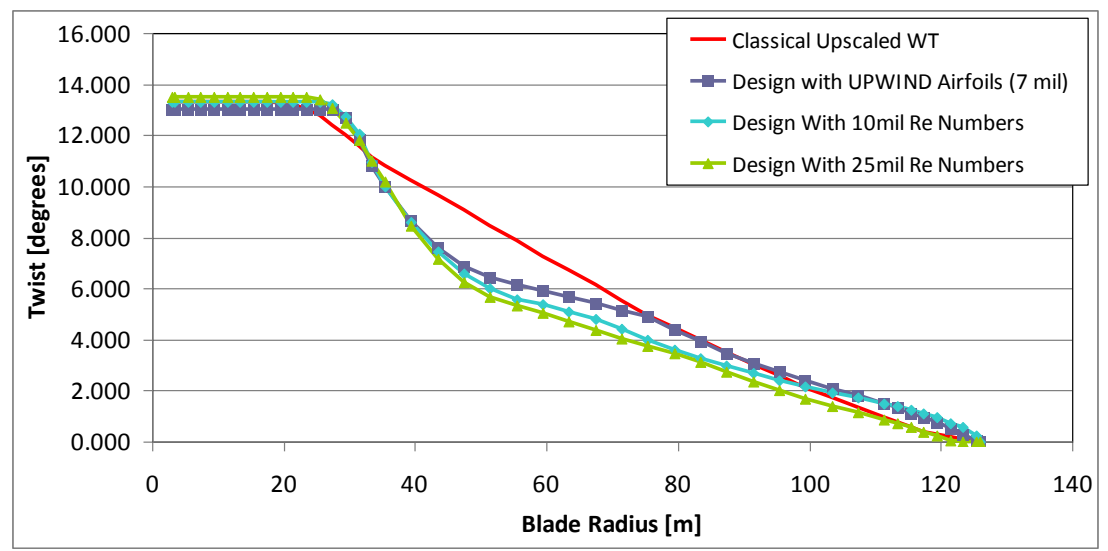

Figure 13. Twist distributions along the blade compared for the different designs.

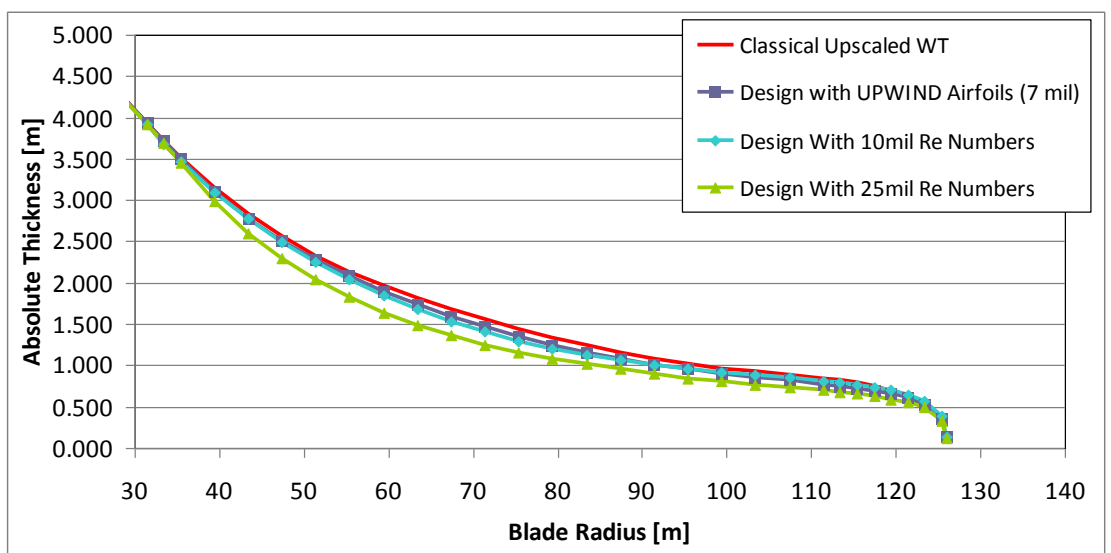

Figure 14. Absolute thickness distributions along the blade compared for the different designs.

When a rotor is upscaled by keeping the relative speed constant along the blade span, together with the tip speed and the tip speed ratio, the only difference in terms of the nondimensional aerodynamics comes from the scale effect which is translated into Reynolds number. Therefore, if there is no change in the local section characteristics of the blade, the rotor $\mathrm{C}_{\mathrm{p}}$ performance will be predicted exactly the same as the smaller rotor. This is why in the Figure 15; the classical upscaled rotor has as high $\mathrm{C}_{\mathrm{p}}$ values as the UPWIND reference rotor. The designed rotors are reaching higher $C_{P}$ values which are almost 0.5 . However, the increase in $C_{p}$ is not very significant. The main difference in the performance is observed in the $\mathrm{C}_{\mathrm{p}}-\lambda$ curves for different pitch angles which are shown in Figure 16. In the classically upscaled turbine, in the design condition $\mathrm{Cp}$ value is just below 0.49 and higher in the lower $\lambda$ values. $\mathrm{C}_{\mathrm{p}}$ 
is above 0.48 between $\lambda=6.75$ and 9 . In the design with high Reynolds numbers, the same $C_{p}$ is obtained in a larger tip speed ratio range which is between 6.75 and 10.5. It shows that in fact this rotor could operate in larger tip speed ratios without losing significant performance. Moreover, in the off design conditions of this rotor, it still operates with a performance which is very close to the design conditions. This gives quite flexibility to the selection of the operating conditions of such a rotor.

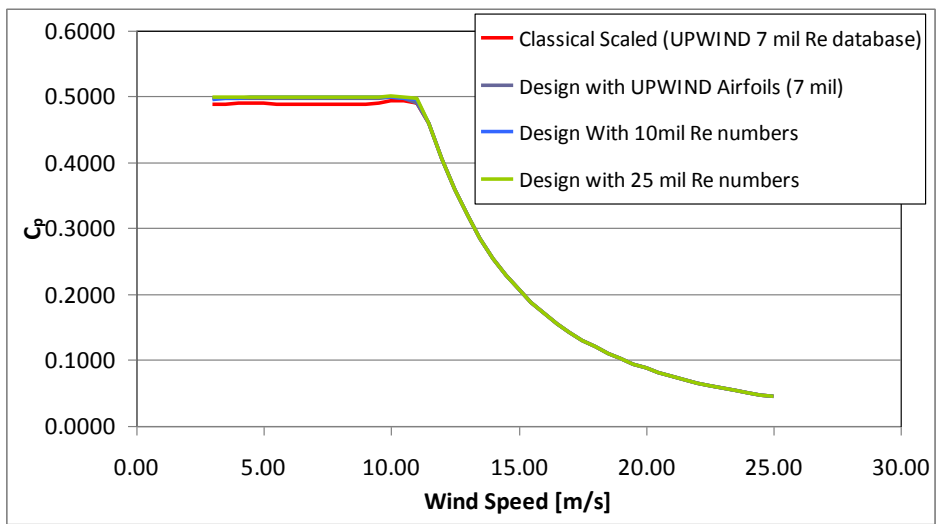

Figure 15. Comparison of the $C_{P}$ performances of the designs.
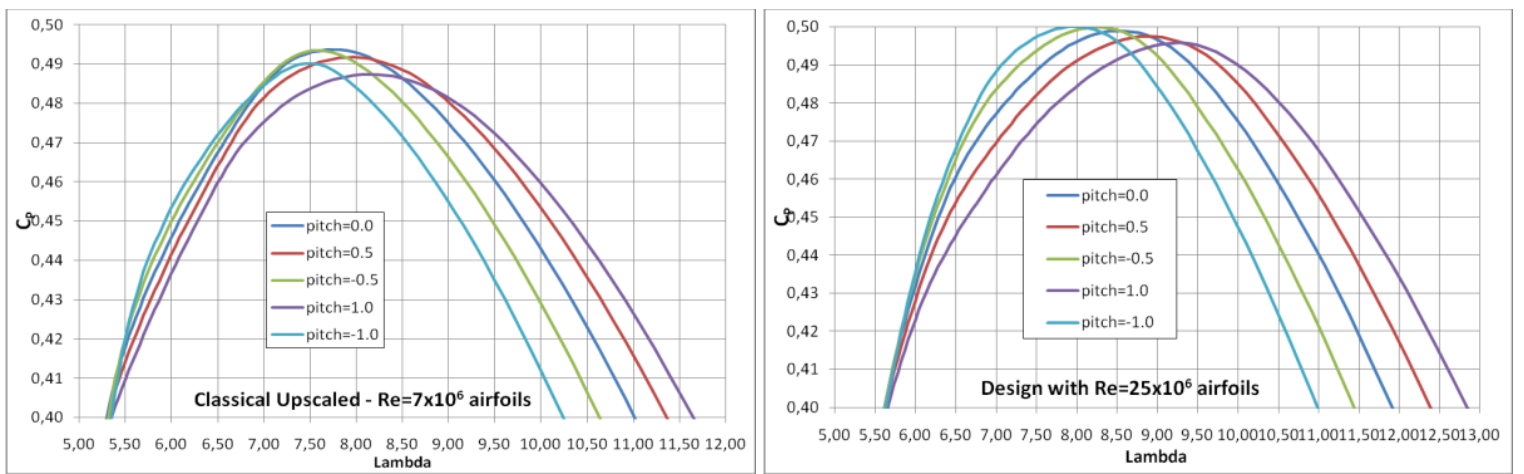

Figure 16. Cp- $\lambda$ curves for classical upscaled rotor and rotor designed with high Reynolds number airfoil database

\section{Conclusions and Discussions}

Growing trends in the wind turbine rotor sizes introduce very Reynolds number operating conditions. There are several effects of the high Reynolds numbers on a design. The airfoils used in the wind turbine rotor applications haven't been tested for such high Reynolds numbers, yet. Therefore, the effects of Reynolds number increase on the airfoil characteristics are predicted by using RFOIL and the existing airfoil data are corrected for the Reynolds effects by using these predictions. RFOIL usually underestimates the effect of Reynolds numbers according to the limited comparison results shown and this gives some confidence about the used method. Although a lot of work is necessary to investigate the effects of very high Reynolds numbers on the design in more detail, some conclusions on the possible effects on the rotor designs can be drawn from this work. By updating the existing airfoil data using the RFOIL predictions for the effects of 20-25 million Reynolds numbers, it is possible to have up to $20 \%$ reductions in the chord distributions along the blade due to the shift of the design condition of the airfoils to higher $C_{1}$ values because of the $C_{1}$ increase and $C_{d}$ decrease. Moreover, the operating conditions of the rotor are spread to a larger tip speed range which brings a lot of flexibility to the application of these rotors.

However, these results are all based on the used correction methods on the airfoil characteristics. The lack of very high Reynolds numbers test data for thick airfoils brings uncertainties to the results. Therefore, the results shown here should be considered as possibilities instead of the real effects of very high Reynolds numbers.

The most important conclusion of this study is the importance of detailed research on very high Reynolds number effects on the performance of wind turbine airfoils. All of the results presented and discussed here have to be proven and investigated more by proper wind tunnel tests. In this perspective, high quality wind tunnel measurements for very high Reynolds numbers are one of the keys to obtain cost effective and reliable wind turbine designs for off shore platforms. 


\section{Acknowledgments}

Author would like to acknowledge Herman Snel for his continuous support and beneficial discussions throughout this work. Author would also like to thank to Arne van Garrel and Johan Peeringa for their valuable contributions.

\section{References}

1“UPWIND: Design Limits and Solutions for Very Large Wind Turbines”, European Sixth Framework Programme, March 2011.

${ }^{2}$ Kooijman, H.J.T, Lindenburg, C., Winkelaar, D., Hoofd E.L. van der, "DOWEC 6MW Pre-Design”, ECN-CX-01-135, Petten, 2003.

${ }^{3}$ Brood, R., Ceyhan, O., Engels, W., Peeringa, J, Winkel, G. de, “UPWIND 20MW Wind Turbine Pre-Design: Blade Design and Control," ECN-E--11-017, 2011.

${ }^{4}$ Haines, A.B., "Scale Effects on Aircraft and Weapon Aerodynamics", edited by Young A.D., AGARD-AG-323, 1999.

${ }^{5}$ Dietz, R.O., et al., "Report of the High Reynolds Number Wind Tunnel Study Group of the Fluid Dynamics Panel", AGARD-AR-35-71, 1971.

${ }^{6}$ Reckzeh, D., Hansen, H., "High Reynolds Number Windtunnel Testing for the Design of Airbus High-Lift Wings", Notes on Numerical Fluid Mechanics and Multidisciplinary Design, 2006, Volume 92/2006.

${ }^{7}$ Rudnik, R., Germain, E., "Re-No. Scaling Effects on the EUROLIFT High Lift Configurations", AIAA-2007-752, 45 AIAA Aerospace Sciences Meeting and Exhibit, Reno, Nevada, January 2007.

${ }^{8}$ Perraud, J. et al., "High Reynolds Number Transition Experiments in ETW (TELFONA Project)", Seventh IUTAM Symposium on Laminar-Turbulent Transition, DOI 10.1007/978-90-481-3723-7_98, Springer Science+Business Media B.V., 2010 .

${ }^{9}$ Timmer, W.A., Rooij, R.P.J.O.M. van, "Summary of the Delft University Wind Turbine Dedicated Airfoils", AIAA-20030352, 2003.

${ }^{10}$ Ansys-CFX, CFD Software for Fluid Flow Modelling, Software Package, Version 11.0, Ansys, 2009.

${ }^{11}$ Drela, M., "XFOIL: An Analysis and Design System for Low Reynolds Number Airfoils," Conference on Low Reynolds Number Airfoil Aerodynamics, University of Notre Dame, 1989.

${ }^{12}$ Snel, H., Houwink, R., Bosschers, J., "Sectional Prediction of Lift Coefficients on Rotating Wind Turbine Blades in Stall," ECN-C--93-052, Petten, the Netherlands, 1994.

${ }^{13}$ Rooij, R. van, "Modification of the Boundary Layer Calculation in RFOIL for Improved Airfoil Stall Prediction", IW96087R, TU Delft, the Netherlands, 1996.

${ }^{14}$ Rooij, R.P.J.O.M. van, and Timmer, V.A, "Roughness Sensitivity Considerations for Thick Rotor Blade Airfoils," AIAA2003-0350, 2003.

${ }^{15}$ Timmer, W.A., Schaffarczyk, A.P., "The effect of roughness at high Reynolds numbers on the performance of DU 97-W300Mod", Wind Energy, Volume 7, Issue 4, pages 295-307, October/December, 2004.

${ }^{16}$ Abbott, H.I., et al., "Summary of Airfoil Data", NACA report no.824, 1944.

${ }^{17}$ Loftin, K.L.,Jr., Bursnall, W.J., "Effects of Variations in Reynolds Number Between 3.0x106 and $25 \times 10^{6}$ upon the Aerodynamic Characteristics of a number of NACA 6-Series Airfoil Sections", NACA-TN-1773, 1948.

${ }^{18}$ Yamauchi, G.K., Johnson, W.,'Trends of Reynolds Number Effects on Two-Dimensional Airfoil Characteristics for Helicopter Rotor Analyses", NASA-TM-84363, 1983.

${ }^{19}$ Freudenreich K., Kaiser K., Schaffarczyk, A.P., Winkler, H., Stahl, B., "Reynolds number and roughness effects on thick airfoils for wind turbines", Wind Engineering, Volume 28, No.5, 2004.

${ }^{20}$ Timmer, W.A., "An Overview of NACA 6-digit airfoil series characteristics with reference to airfoils for large wind turbine

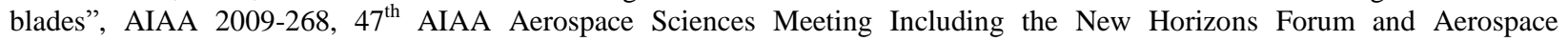
Exposition, January 2009, Orlando, Florida.

${ }^{21}$ Menter, F. R., "Two-equation Eddy-Viscosity Turbulence Models for Engineering Applications", AIAA Journal, v.32, p.1598-1605, 1994.

${ }^{22}$ Bot, E.T.G, Ceyhan O., "BOT-Blade Optimization Tool User Manual," ECN-E--09-092, Petten, the Netherlands, 2009.

${ }^{23}$ Ceyhan, O., Bot, E.T.G., "Validation of the ECN Blade Optimization Tool BOT," ECN-X--09-140, Petten, the Netherlands, 2009.

${ }^{24}$ Freris, L.L. "Wind Energy Conversion Systems", Prentice Hall International, UK, 1990.

${ }^{25}$ Bot, E.T.G, “Aerodynamische Tabel Generator, Handleiding,” ECN--01-077, 2001.

${ }^{26}$ Chaviaropoulos, P., "Similarity Rules for WT Upscaling", UPWIND Project Report, Deliverable 1B4-D1, 2006.

${ }^{27}$ Abbott, H.I., Doenhoff, A.E.V., "Theory of Wing Sections”, Dover Publications, New York, 1959.

${ }^{28}$ Schaffarczyk, A.P., et al., "Reynolds number effects on thick aerodynamic profiles for wind turbines", European Wind Energy Conference, Madrid, Spain, 2003. 